\title{
Microstructural and mechanical characterization of nitrogen ion implanted layer on 316L stainless steel
}

\author{
O. Öztürk* \\ Department of Physics, Izmir Institute of Technology, Urla, Izmir 35430, Turkey
}

\section{A R T I C L E I N F O}

\section{Article history:}

Available online 30 January 2009

\section{PACS:}

68.55.Ln

$76.80 .+y$

62.20.Qp

61.05. $-\mathrm{a}$

Keywords:

Nitrogen implantation

XRD

Mössbauer spectroscopy

Nanohardness

\begin{abstract}
A B S T R A C T
Nitrogen ion implantation can be used to improve surface mechanical properties (hardness, wear, friction) of stainless steels by modifying the near-surface layers of these materials. In this study, a medical grade FeCrNi alloy (316L stainless steel plate) was implanted with $85 \mathrm{keV}$ nitrogen ions to a high fluence of $1 \times 10^{18} \mathrm{~N}_{2}^{+} / \mathrm{cm}^{2}$ at a substrate temperature $<200{ }^{\circ} \mathrm{C}$ in an industrial implantation facility. The $\mathrm{N}$ implanted layer microstructures, thicknesses and strengths were studied by a combination of X-ray diffraction (XRD), conversion electron Mössbauer spectroscopy (CEMS), atomic force microscopy (AFM) and nanohardness measurements. AFM was also used for the surface roughness analysis of the implanted as well as polished materials. The CEMS analysis indicate that the $\mathrm{N}$ implanted layer is $\sim 200 \mathrm{~nm}$ thick and is composed of $\varepsilon-(\mathrm{Fe}, \mathrm{Cr}, \mathrm{Ni})_{2+x} \mathrm{~N}$-like nitride phase with mainly paramagnetic characteristics. The nanohardness measurements clearly indicate an enhanced hardness behaviour for the $\mathrm{N}$ implanted layer. It is found that the implanted layer hardness is increased by a factor of 1.5 in comparison to that of the substrate material. The increased hardness resulting from nitrogen implantation is attributed to the formation of $\varepsilon$ nitride phase.
\end{abstract}

(c) 2009 Elsevier B.V. All rights reserved.

\section{Introduction}

316L stainless steel (SS) is compositionally disordered $\mathrm{Fe}, \mathrm{Cr}, \mathrm{Ni}$ and Mo alloy with the face-centered cubic (fcc) structure of the austenite (the $\gamma$-Fe). This particular alloy is used as an implant material to make internal fixation devices (artificial joints, bone plates, stents) due to its favorable combination of mechanical properties, corrosion resistance, satisfactory biocompatibility and cost effectiveness compared with other metallic biomaterials [1]. However, 316L SS and other austenitic stainless steel types (such as 304,310 SS) are rather soft materials and often suffer from a high amount of wear caused by mechanical loads [2].

Hardness and wear resistance improvement of 316L SS alloy and other austenitic varieties can often be accomplished by an appropriate surface modification technique. Nitrogen ion implantation has been shown to improve the wear resistance of prosthetic components such as the knee and hip replacements [3,4]. In the implantation process, nitrogen atoms are ionized, accelerated to a high energy and then ballistically penetrate into the near-surface layer of the component to be treated. Literature studies indicate that the implantation of nitrogen ions induces nitride formation, which makes the implanted surface very hard [5-7]. For conventional nitrogen ion energies $(\sim 100 \mathrm{keV})$, the thickness of the nitride layer

\footnotetext{
* Tel.: +90 232750 7708; fax: +90 2327507707 .

E-mail address: orhanozturk@iyte.edu.tr
}

is of the order of $100 \mathrm{~nm}$. An important advantage of the nitride formation by the implantation is the good adhesion of the nitride layer to the substrate [8]. Another benefit of ion implantation for surgical materials is its ability to modify surface properties without almost no dimensional change compared with various coating methods such as PVD and ion beam assisted deposition [9]. Also, compared with the standard diffusion processes such as plasma nitriding, under conventional implantation conditions, the surface finish of the parts to be implanted may not be altered much (the implanted surface is recessed by sputtering but the change is small), and this may be an important factor affecting the corrosion resistance and biocompatibility of surgical alloys such as $316 \mathrm{~L} \mathrm{SS}$.

In this study, we investigate the influence of conventional nitrogen ion beam implantation conditions on the formation of the nitride layer on medical grade 316L SS alloy. The hardness behaviour of the $\mathrm{N}$ implanted layer will also be investigated. This study combines the use of X-ray diffraction (XRD), conversion electron Mössbauer spectroscopy (CEMS) and nanohardness measurements. The roughness behaviour of the $\mathrm{N}$ implanted surfaces as well as as-polished ones will be analysed by atomic force microscopy (AFM).

\section{Experimental details}

Medical grade 316L stainless steel with a base chemical composition of $17 \% \mathrm{Cr}, 15 \% \mathrm{Ni}, 3 \% \mathrm{Mo}, 2 \% \mathrm{Mn}$ and balance $\mathrm{Fe}$ (all in wt.\%), 
was the material into which $\mathrm{N}$ was implanted. The implantation treatment was carried out in an industrial implantation facility (Implant Sciences). Before implantation, two specimens with a squarelike geometry $(2.5 \mathrm{~cm}$ on the side and $0.20 \mathrm{~cm}$ thick) were polished to mirror-like quality with a mean surface roughness of about $\sim$ $5 \mathrm{~nm}$ based on atomic force microscopy (AFM). One of the polished plate specimens was implanted with nitrogen ions from the gaseous implanter (ion beam was not mass-analysed) to a high fluence of $1 \times 10^{18}$ ions $/ \mathrm{cm}^{2}$ at substrate temperature of $<200{ }^{\circ} \mathrm{C}$. The implantation current density and the ion beam energy were $\sim 3 \mu \mathrm{A} / \mathrm{cm}^{2}$ and $85 \mathrm{keV}$, respectively. The substrate temperature was due to the ion beam (no external heating). The actual substrate temperature is believed to be much less than $200^{\circ} \mathrm{C}$ (about $100{ }^{\circ} \mathrm{C}$ ) due to low current density of the ion beam used by the system.

Near-surface crystal structures of the $\mathrm{N}$ implanted as well as polished samples were analysed by symmetric $\theta / 2 \theta$ (Bragg-Brentano) X-ray diffraction (XRD) using a Philips X'pert XRD system with $\mathrm{Cu}-\mathrm{K} \alpha$ radiation. The near-surface phases were also characterized by conversion electron Mössbauer spectroscopy (CEMS). After the XRD analyses of the $\mathrm{N}$ implanted sample (sample code I1) and the polished substrate sample (sample code S7), each of these two samples were cut into four equal square sections. The Mössbauer analysis was performed on one of the square sections (labeled as I1-4 for the N implanted sample section and as S7-1 for the polished sample section). The rest of the square sections were used for the other experimental analyses described below. The CEMS technique is ideal for studying thin $\mathrm{N}$ implanted layers since the CEMS signal comes from depths up to $\sim 300 \mathrm{~nm}[10]$. The CEMS signal is normally composed of resonant components characteristic of phases distributed in the layer probed by the conversion electrons. In this study, the CEMS method mainly allowed quantitative Fe-containing phase analysis of the near-surface region and this, in return, was used to estimate the nitrided layer thickness. Average roughness Ra was measured by AFM (Nanoscope IV) for both polished and $\mathrm{N}$ implanted 316L SS specimens. At least three readings were taken for each surface tested. The nanohardness profile of the $\mathrm{N}$ implanted layer was obtained using a CSEM tester equipped with a Vickers indentor. The loads for nanoindentation were $10,25,50,100$ and $200 \mathrm{mN}$. Typically, five indentations were made for each load. The as-polished substrate hardness was measured with a microhardness tester (Zwick Roell) also equipped with a Vickers indentor. In this case, the applied loads were $200 \mathrm{mN}$ and $1 \mathrm{~N}$.

\section{Results and discussion}

The XRD results for the as-polished substrate and $\mathrm{N}$ implanted 316L SS specimens are shown in Fig. 1. In this figure, the fcc substrate peaks are labeled as $\gamma(\mathrm{hkl})$ and the implantation induced ones as $\varepsilon$. The results clearly indicate that the $\mathrm{N}$ implanted layer is composed of the hexagonal nitride phase $\varepsilon-(\mathrm{Fe}, \mathrm{Cr}, \mathrm{Ni})_{2+x} \mathrm{~N}$. The $\varepsilon$ nitride formation is consistent with previous studies, where it was almost always observed when the implantation temperature was in the range $\sim 200-350{ }^{\circ} \mathrm{C}[10,11]$. The broader nature of the $\varepsilon-(\mathrm{Fe}, \mathrm{Cr}, \mathrm{Ni})_{2+{ }_{x}} \mathrm{~N}$ peaks in Fig. 1 suggest a range of nitrogen content (i.e. a range of $x$ ) or concentration gradient distribution in the implanted layer [11].

Fig. 2 shows the CEMS results for the $\mathrm{N}$ implanted and the $316 \mathrm{~L}$ SS substrate specimens, and Table 1 gives the quantitative Mössbauer results for these samples. The CEMS spectrum of the as-polished substrate sample (S7-1) is composed of the paramagnetic austenite phase only (broadened single line resonance). The

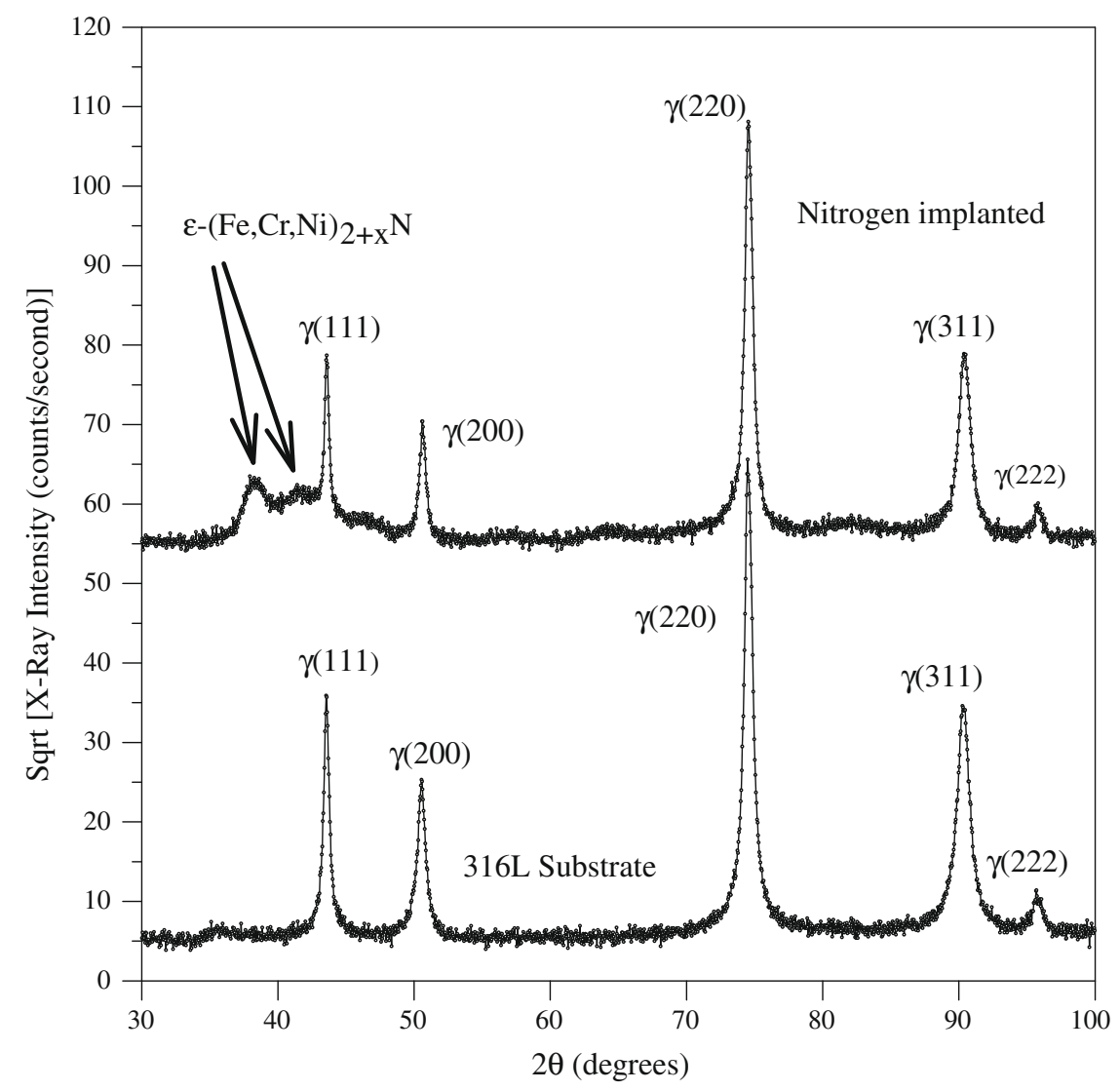

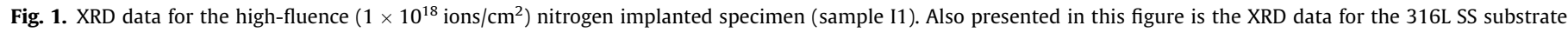
alloy (sample S7). 


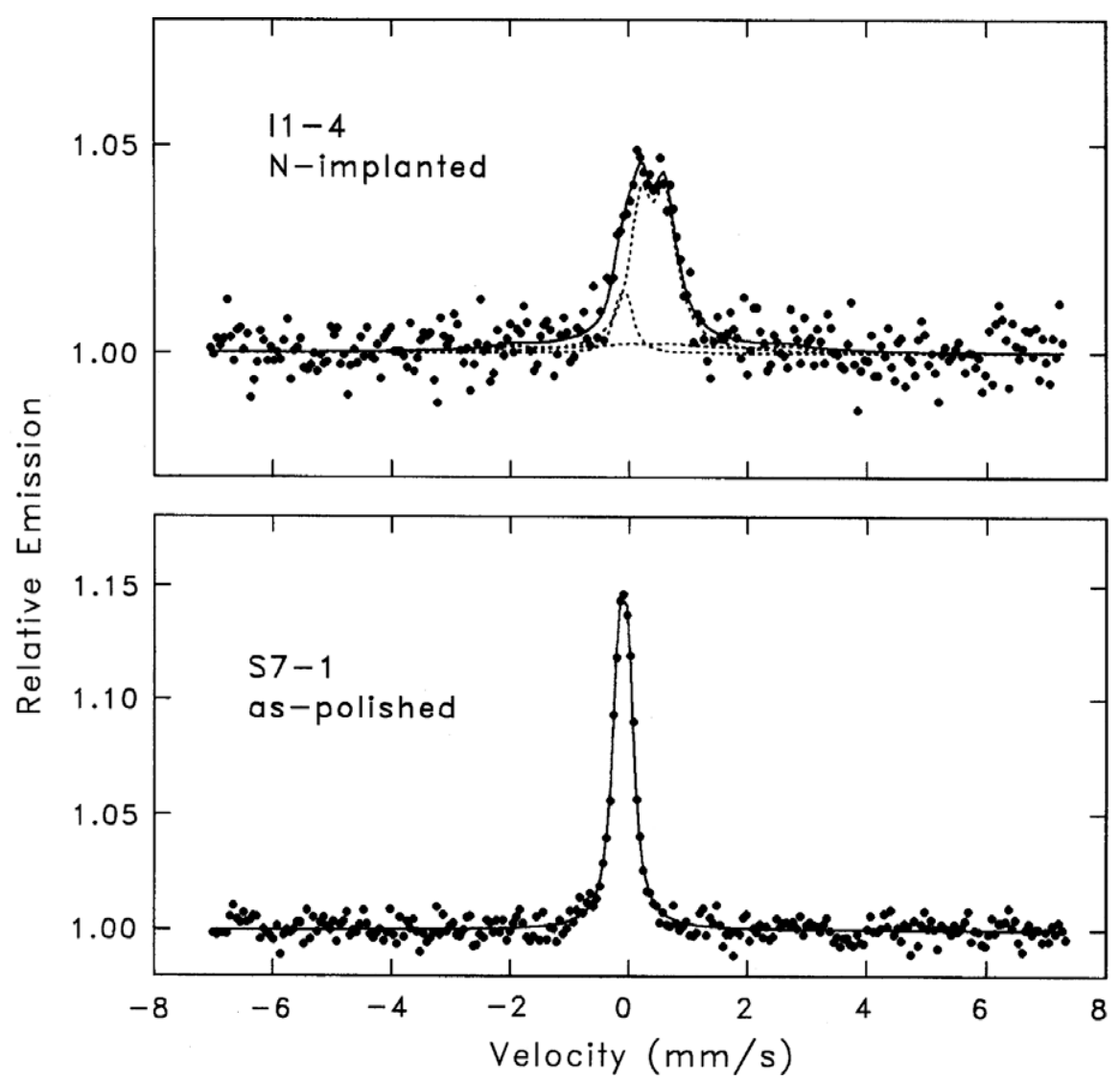

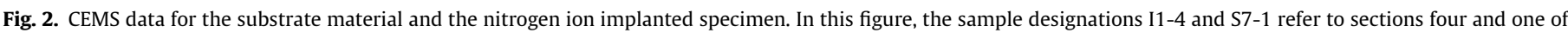

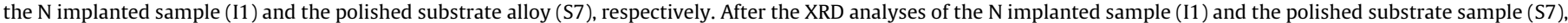
each of these two samples were cut into four equal square sections. The other sections were used for AFM and hardness analyses.

Table 1

Mössbauer (CEMS) hyperfine parameters and resonance fractions for the nitrogen implanted as well as the as-polished (substrate) specimen. All measurements were made at room temperature. $\delta$ and $\Delta$ is isomer shift (relative to pure $\alpha$-Fe foil) and quadrupole splitting in $\mathrm{mm} / \mathrm{s}$ and $H$ is the hyperfine field in Tesla. $F$ is the relative resonance area fraction in percent. Numbers in parentheses represent statistical uncertainty in the last significant figure and $\mathrm{f}$ in parentheses indicates the parameter was fixed. SS number refers to subspectrum number.

\begin{tabular}{llllll}
\hline SS number & \multicolumn{5}{l}{ CEMS } \\
\cline { 3 - 6 } & & $\delta$ & $\Delta$ & $H$ & \multicolumn{1}{l}{} \\
\hline As-polished & SS1 & $-0.09(1)$ & $0.16(2)$ & - & 100 \\
N implanted & SS1 & $0.41(3)$ & $0.41(4)$ & - & $70(5)$ \\
& SS2 & $-0.09(\mathrm{f})$ & $0.16(\mathrm{f})$ & - & $10(5)$ \\
& SS3 & $0.35(10)$ & - & $14(4)$ & $20(10)$ \\
\hline
\end{tabular}

CEMS spectrum of the $\mathrm{N}$ implanted sample (I1-4) is composed of the paramagnetic austenite phase [substrate $\gamma$-( $\mathrm{Fe}, \mathrm{Cr}, \mathrm{Ni})$ phase], an implantation induced doublet (quadrupole doublet), whose Mössbauer parameters are similar to paramagnetic $\varepsilon-\mathrm{Fe}_{2+x} \mathrm{~N}$ where $x$ is near 0 [here, we must have $\varepsilon-(\mathrm{Fe}, \mathrm{Cr}, \mathrm{Ni})_{2+x} \mathrm{~N}$ with $x \sim 0$ ], and a magnetic component (a broad six-line pattern) with Mössbauer parameters similar to that of magnetic $\varepsilon-\mathrm{Fe}_{2+x} \mathrm{~N}$ where $x$ is near 0.5 [12]. The CEMS findings of the $\varepsilon$-nitride phase, [ $\varepsilon$ $\left.(\mathrm{Fe}, \mathrm{Cr}, \mathrm{Mn})_{2+x} \mathrm{~N}\right]$, correlate quite well with those of the XRD results (Fig. 1).

From the fitting of the CEMS data in Fig. 2, the CEMS resonance area fractions for the $\mathrm{N}$ implanted sample are found to be $10 \%$ for the substrate phase, $70 \%$ for the paramagnetic nitride and $20 \%$ for the magnetic nitride (Table 1 ). The total resonance fraction of nitrides for the $\mathrm{N}$ implanted sample is $90 \%$, and based on a uniform layer of nitride phase assumption [13], the thickness of the nitride layer is estimated to be $\sim 200 \mathrm{~nm}$. This thickness value, however, is only a rough estimate since there is a big uncertainty (10\%) in the magnetic component (it is buried in the scatter). The resonance fraction versus depth curve in [13] is rather flat in the range from 100 to $200 \mathrm{~nm}$ so it would not take much of an error in the $90 \%$ value to reach $100 \mathrm{~nm}$ rather than $200 \mathrm{~nm}$. If the total nitride fraction is taken to be that of the paramagnetic one (70\%), the curve in [13] predicts a $80-85 \mathrm{~nm}$ thick nitride layer, and this is probably more in line with what is predicted by TRIM calculations [14]. Based on TRIM analysis, the ballistic depth range for $85 \mathrm{keV} \mathrm{N}^{+}$ions is estimated to be $\sim 90 \mathrm{~nm}$ in the target material of this study.

In conclusion, the quality of the CEMS data is not good enough (due to a weak Mössbauer source as well as due to the small size of the implanted sample) to make an accurate estimate of the layer thickness. In fact, it is believed that the nitride layer thickness is overestimated in light of the fact that the substrate temperature during implantation was less than $200^{\circ} \mathrm{C}$. The substrate temperature during the implantation was due to the ion beam and was not measured; however, we believe that the temperature is much lower than $200^{\circ} \mathrm{C}$ (about $100^{\circ} \mathrm{C}$ ) due to low current density of the ion beam used by the system. It would be best to somehow get a nitrogen depth profile by AES or GDOES.

Fig. 3 compares 3D AFM images of the $\mathrm{N}$ implanted and as-polished (un-implanted) 316L SS surfaces. The AFM image of the as-polished substrate surface shows that it is relatively smooth and featureless. The AFM results indicate that the surface roughness is increased only slightly by nitrogen ion implantation. While the average roughness value ( $\mathrm{Ra}$ ) for the as-polished substrate is found to be $\sim 5 \mathrm{~nm}$, it is $\sim 7 \mathrm{~nm}$ for the $\mathrm{N}$ implanted surface. 


\section{L SS Substrate}

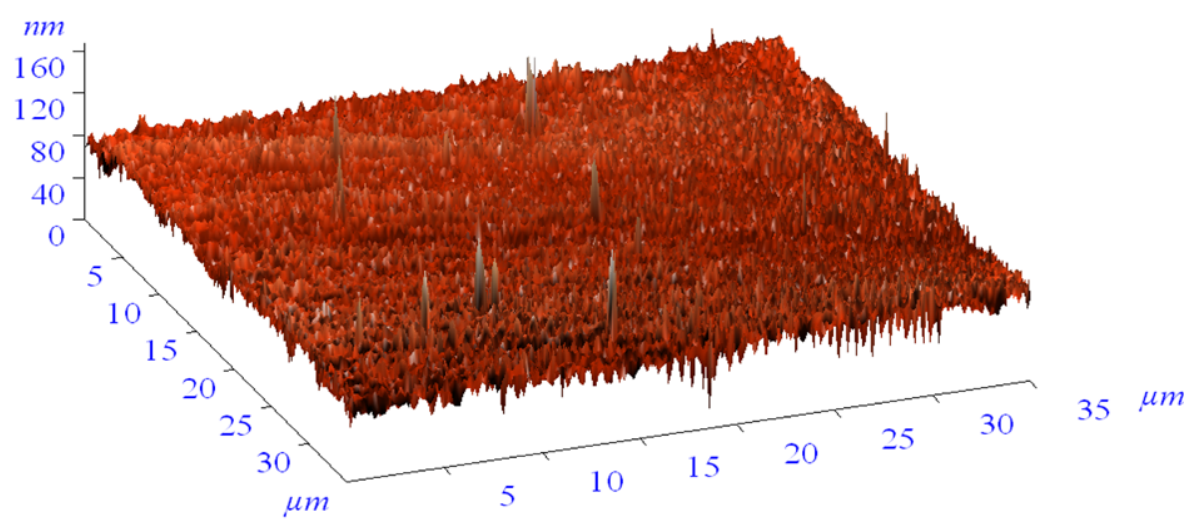

N Implanted 316L SS

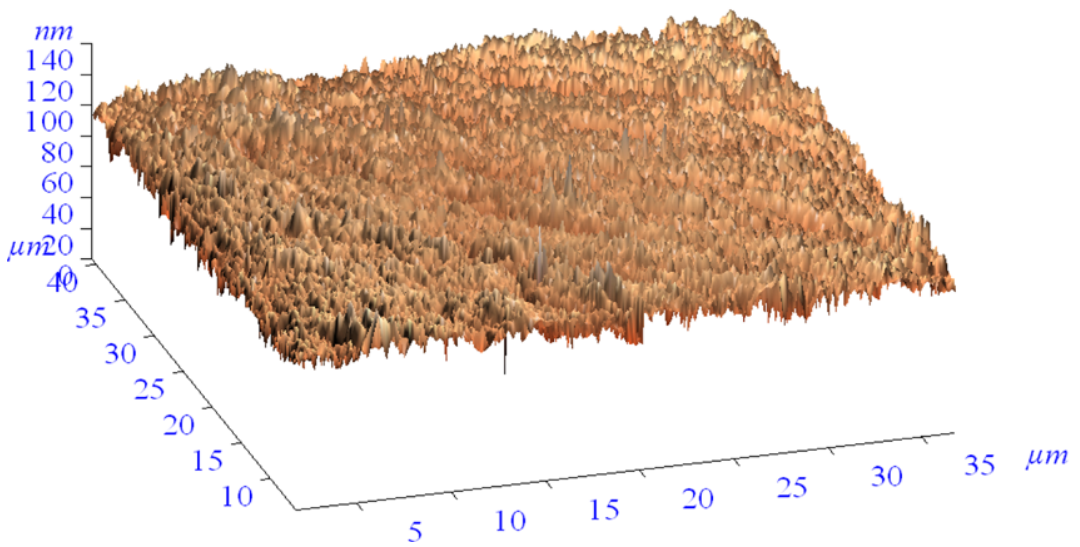

Fig. 3. 3D AFM images for the $\mathrm{N}$ implanted as well as the substrate material surfaces.

The average nanohardness values for the nitrogen ion implanted specimen are plotted in Fig. 4 as a function of the indentor load. The hardness value at the lightest load $(10 \mathrm{mN})$ is near $\sim 800 \mathrm{HV}$ for the $\mathrm{N}$ implanted specimen. As can be seen from Fig. 4, the hardness values for the $\mathrm{N}$ implanted layer continuously decrease to smaller values as the indentor load is increased. This can be explained by the fact that, at high loads, the indentor probe depth probably exceeds the thickness of the $\mathrm{N}$ implanted layer, resulting in a significant contribution of the substrate phase $[\gamma$ $(\mathrm{Fe}, \mathrm{Cr}, \mathrm{Ni})]$. A comparison of the average hardness values at the

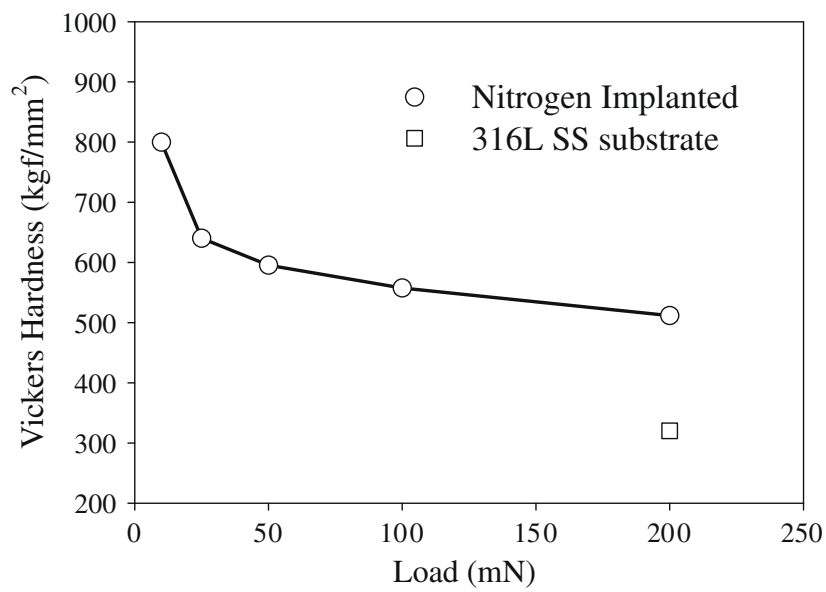

Fig. 4. Nanohardness data for the $\mathrm{N}$ implanted 316L SS alloy. The hardness value for the as-polished substrate is also included for comparison purposes.
$200 \mathrm{mN}$ load (about $512 \mathrm{HV}$ for the $\mathrm{N}$ implanted sample versus $\sim 320 \mathrm{HV}$ for the substrate) suggests the hardness for the implanted layer is higher than that of the substrate by a factor of 1.6.

Enhanced hardness behaviour observed here is mainly attributed to nitride formation and to sufficient layer thickness. Literature studies indicate that due to the formation of nitride precipitates, the implanted layer becomes very hard [6,9]. Also, the increased hardness resulting from nitrogen implantation may be due to stresses. The literature also indicates that nitrogen implantation into metals produces a substrate stress profile which restricts the entrance of dislocations from the surface and, therefore, contributes to the hardening [9].

\section{Conclusions}

In this study, structural and hardness behaviour of high-fluence $\left(1 \times 10^{18}\right.$ ions $\left./ \mathrm{cm}^{2}\right) \mathrm{N}$ implanted surgical grade $316 \mathrm{~L}$ SS was investigated. Combined Mössbauer spectroscopy and X-ray diffraction analyses provide strong evidence for the formation of a hexagonal type $\varepsilon$-nitride phase, $\left[\varepsilon-(\mathrm{Fe}, \mathrm{Cr}, \mathrm{Ni})_{2+x} \mathrm{~N}\right]$, with mainly paramagnetic characteristics. Based on the CEMS data, the thickness of the $\varepsilon$-nitride layer is estimated to be $\sim 200 \mathrm{~nm}$. The nanohardness measurements suggest enhanced hardness behaviour for the $\mathrm{N}$ implanted specimen compared with that of the substrate material. The increase in hardness is attributed to the implantation induced crystal structures, i.e. $\varepsilon$-nitride, and to sufficient implanted layer thickness. As a result of the nitrogen ion implantation, the AFM results show that the surface roughness of the $\mathrm{N}$ implanted surface is not altered much compared to the polished substrate. 


\section{Acknowledgements}

The authors are grateful to Hipokrat A.Ş. for providing medical grade 316L SS materials for this study and to Professor Don L. Williamson of Colorado School of Mines for Mössbauer measurements. Professor Ahmet Öztarhan of Ege University is acknowledged for performing the $\mathrm{N}$ implantation. This Project was partially funded by Tubitak (National Science Foundation of Turkey) through Grant TBAG-2444.

\section{References}

[1] J.A. Disegi, L. Eshbach, Injury 31 (2000) 2.
[2] R. Günzel, M. Betzl, I. Alphonsa, B. Ganguly, P.I. John, S. Mukherjee, Surf. Coat. Technol. 112 (1999) 307.

[3] R. Hutchings, W.C. Oliver, Wear 92 (1983) 143.

[4] W. Ensinger, Surf. Coat. Technol. 100-101 (1998) 341.

[5] A.M. Kliauga, M. Pohl, D. Kaffke, Surf. Coat. Technol. 102 (1998) 237.

[6] B.R. Lanning, R. Wei, Surf. Coat. Technol. 186 (2004) 314

[7] O. Öztürk, O. Onmus, D.L. Williamson, Surf. Coat. Technol. 196 (2005) 333.

[8] S. Fukumoto, H. Tsubakino, S. Inoue, L. Liu, M. Terasawa, T. Mitamura, Mater. Sci. Eng. A326 (1999) 205.

[9] Y. Miyagawa, S. Nakao, M. Ikeyama, K. Saitoh, S. Miyagawa, Nucl. Instr. and Meth. B 121 (1997) 340.

[10] O. Öztürk, D.L. Williamson, J. Appl. Phys. 77 (1995) 3839.

[11] O. Ozturk, D.L. Williamson, Hyperfine Interact. 92 (1994) 1329.

[12] G.M. Chen, N.K. Jaggl, J.B. Butt, L.H. Schwartz, J. Phys. Chem. 87 (1983) 5326.

[13] D.L. Williamson, F.M. Kustas, D.B. Fobare, M.S. Misra, J. Appl. Phys. 80 (1986) 1493.

[14] J.F. Ziegler, J.P. Biersack, U. Littmark, TRIM version 92.1. 